\title{
DEVELOPMENT AND RESEARCH OF COMPONENTS OF THE GAS-GENERATOR COMPOSITIONS BASED ON POTASSIUM CHLORATE
}

\author{
M.I. Tulepov ${ }^{1}$, D.A. Baiseitov ${ }^{1}$, Sh.E. Gabdrashova ${ }^{1}$, L.R. Sassykova ${ }^{1 *}$, Y.V. \\ Kazakov $^{1}$, S. Tursynbek ${ }^{1}$, K. Toshtay ${ }^{2}$, I.O. Pustovalov ${ }^{1}$, F.Y. Abdrakova ${ }^{1}$, \\ Z.A. Mansurov ${ }^{1}$ and A.B. Dalton ${ }^{3}$ \\ ${ }^{1}$ Al-Farabi Kazakh National University, 050040, Almaty, Kazakhstan \\ ${ }^{2}$ Scientific Technology Park, 050040, Almaty, Kazakhstan \\ ${ }^{3}$ Department of Physics, University of Surrey, Guildford, \\ Surrey GU27XH, United Kingdom \\ *E-mail : larissa.rav@mail.ru
}

\begin{abstract}
The purpose of this study is the development and investigation of gas-generating composition based on potassium chlorate for the destruction of a stone. The thermodynamic analysis of the energy characteristics of the studied gasgenerating compositions was carried out. Influence of various amounts of nano-aluminium on features and regularities of burning and ignition of pyrotechnic gas-generating composition on the basis of potassium chlorate was studied. By results of thermodynamic calculation and experimental work the optimum gas-generating composition for destruction of a stone - $\mathrm{KClO}_{3}-72 \%$, polyethylene $-17 \%$, nano - aluminium Alex-11\% was chosen. The carried-out polygon tests on the destruction of a stone had shown high efficiency of use of this gas-generating composition for destruction of a stone.
\end{abstract}

Keywords: gas-generator composition, blasthole, stone, nano-aluminum, pyrotechnics

@ RASĀYAN. All rights reserved

\section{INTRODUCTION}

Recently, in the extraction of block stone, the effective gas-generator compositions are used. Gasgenerating compositions are laid in blast holes with a diameter of at least $28 \mathrm{~mm}$, a length of at least 80 $\mathrm{mm}$, laying is carried out along the blast hole line in the temperature regime from -30 to $+35^{\circ} \mathrm{C}$, without using the energy of the explosion.

When initiating the gas-generator composition in the hole, there is a rapid combustion or deflagration combustion, due to the release of gaseous products, an effort is created to break the monolith ${ }^{1,2}$. So, for example, at the Mining University (St. Petersburg, Russia), the scientific works are being carried out to create gas-generator chemical cartridges (GGCC), in which the destruction of the construction takes place in a sparing mode. ${ }^{3}$

It is known that pyroxylin artillery powder and ballistic rocket solid fuel are a solid gas generating materials. ${ }^{4,5}$ During the combustion of these substances, gaseous products of up to $1000 \mathrm{ml} / \mathrm{kg}$ are released. The combustion temperature of the lowest low-energy ballistite, capable of sustainably burning at pressures not lower than $4 \mathrm{MPa}$, is $1,327-1,427^{\circ} \mathrm{C}$.

On the basis of the analysis of the carried out experimental studies on the combustion of gas-generator compositions published in the scientific literature, in this work, potassium chlorate $\left(\mathrm{KClO}_{3}\right)$ was chosen as the oxidant for gas-generating mixtures, polyethylene (PE) was chosen as the fuel and the energy additive was aluminum. Compositions based on potassium and sodium perchlorates with polyethylene have sufficiently high energy characteristics, burn steadily at normal pressures, but have a disadvantage high $\operatorname{cost}^{6}$. Compositions based on sodium and potassium nitrate, compared to chlorates, have a lower energy. Even greater energy characteristics can be obtained by using ammonium perchlorate, but also

Rasayan J. Chem., 10(4), 1145-1150(2017)

http://dx.doi.org/10.7324/RJC.2017.1041878 
have a disadvantage - high cost and greater sensitivity to mechanical influences. ${ }^{7}$ Compositions based on sodium and potassium chlorates are cheaper and safe to handle.

The aim of the work is the development and investigation of gas-generating composition based on potassium chlorate for the destruction of stone.

\section{EXPERIMENTAL}

Compositions were prepared with a different ratio of components, potassium chlorate powder was used as an oxidizer, polyethylene granules $2-8 \mathrm{~mm}$ in size as a fuel; PA-4 aluminum powders of 65 microns in size and Alex grade nano-aluminium with a dispersion of 90-110 $\mathrm{nm}$ were used as an energy additive.

In this paper, the experimental part was carried out by methods described in the literature and elaborated by authors of this article. ${ }^{8-13}$

The burning rate of the compositions was measured by the method of blown wires. ${ }^{14,15}$

To determine the delay in the ignition of the compositions, compressed samples with a diameter of $5 \mathrm{~mm}$ and a height of $1.5 \mathrm{~mm}$ were prepared. Cylindrical samples were made by pressing with a hydraulic press of grade PGPr. The density of the pressed samples was in the range $1.5-1.8 \mathrm{~g} / \mathrm{cm}^{3}$. The samples were pressed at a pressure up to $1,340 \mathrm{~kg} / \mathrm{cm}^{2}$. The ignition experiments were carried out at atmospheric pressure under the action of a $\mathrm{CO}_{2}$ laser.

Thermodynamic calculations were calculated at a pressure of $0.1 \mathrm{MPa}$ according to the $\operatorname{program}^{10}$, advanced and intended for computer operation. The TERRA program is based on the principle of maximum entropy, has an extensive database of the thermodynamic properties of substances and allows complete information of thermodynamic analysis.

The program is characterized by high speed and ease of use. To enter the TERRA program, the initial composition of the feed in mole fractions, the pressure $\mathrm{P}=0.1 \mathrm{MPa}$, and the enthalpy of formation $\mathrm{I}_{\text {initial }}$ are given.

The destruction of the stone into separate blocks was carried out according to the scheme shown in Figure-1.

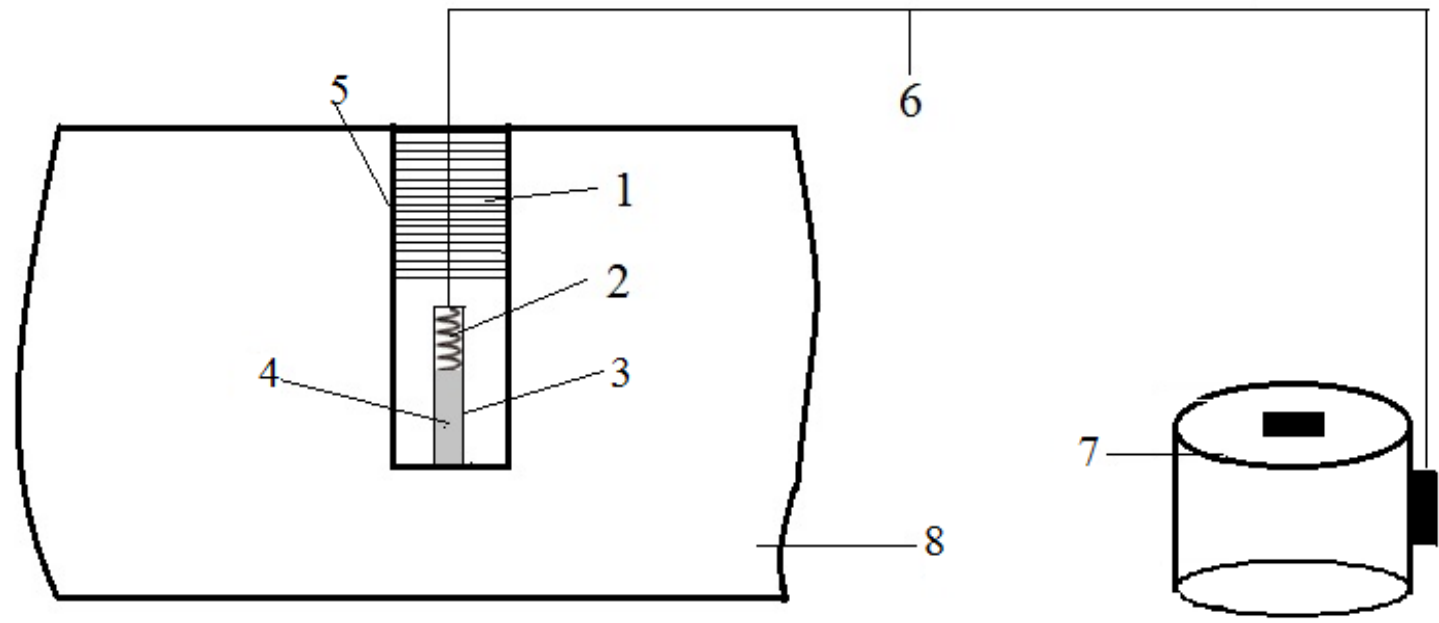

Fig.-1: Experimental Scheme: 1 - quickly grasp mixture (cement $+\mathrm{CaCl}_{2}$ ); 2 - filament of incandescence; 3- gas generator cartridge; 4- pyrotechnic gas-generator composition; 5-blast hole; 6 - cable; 7 - the laboratory autotransformer; 8 - stone

Drilling of the blast hole (5) was carried out by manual perforators. The diameter of the blast hole is 5 $\mathrm{cm}$. The depth of the blast hole is $30 \mathrm{~cm}$. To create a closed volume, the mouth of the blast hole was hermetically sealed with fast-hardening mixtures (1). Charges (4) in the blast holes were formed from a cardboard cartridge (3), a cartridge diameter of $30 \mathrm{~mm}$, a height of $40 \mathrm{~mm}$. Initiation of the charge was carried out with the help of an incandescent spiral (2), the end pieces of the spiral were connected to the cables (6). The impulse was fed from the laboratory autotransformer (7) through the cable. 
RASĀYAN $J$. Chem.

Vol. 10 | No. 4 |1145-1150 | October - December | 2017

\section{RESULTS AND DISCUSSION}

From literature ${ }^{16-18}$ it is known that by the introduction of aluminum to the gas-generating mixture $\mathrm{KClO}_{3}$-polyethylene it is possible to raise energy characteristics of this composition.

For determination of optimum composition and their efficiency of use, a series of calculations of parameters of the burning of gas-generating composition $\mathrm{KClO}_{3}$-polyethylene-Al was carried out. The mass ratio of oxidizer and fuel in the composition was assumed to be equal to:

$\mathrm{KClO}_{3} /$ polyethylene $=0.81 / 0.19$.

The mass fraction of aluminum in the gas-generator composition varied from 1 to $13 \%$.

The basic design parameters for the combustion of the compositions are given in Table- 1 . The values of the enthalpy $\mathrm{I}$, the adiabatic temperature $\mathrm{T}$ adiabatic, the equilibrium adiabatic index $\mathrm{k}$, the number of moles $\mathrm{M}$, the mass fraction of the condensed phases $\mathrm{z}$, the gas constant $\mathrm{R}$, and the efficiency of the combustion products RT are given. The calculated values of gas-productivity of the studied compositions are given in Table- 2 .

Table-1: Thermodynamic characteristics of the test compounds

\begin{tabular}{c|l|c|c|c|c|c|c|c}
\hline No. & Composition & $\begin{array}{c}\mathrm{I}, \\
\mathrm{kJ} / \mathrm{kg}\end{array}$ & $\mathrm{T}_{\mathrm{ad}}, \mathrm{K}$ & $\mathrm{M}, \mathrm{mol} / \mathrm{kg}$ & $\mathrm{R}, \mathrm{J} / \mathrm{kg} \cdot \mathrm{K}$ & $\begin{array}{c}\mathrm{RT}, \\
\mathrm{kJ} / \mathrm{kg}\end{array}$ & $\mathrm{k}$ & $\begin{array}{c}\mathrm{z}, \\
\%\end{array}$ \\
\hline 1 & $\begin{array}{l}\mathrm{KClO}_{3}-80.19 \% \\
\mathrm{PE}-18.81 \\
\mathrm{Al}-1 \%\end{array}$ & $-3,350$ & 1,510 & 32.708 & 275.61 & 416.2 & 1.2115 & 1.9 \\
\hline 2 & $\begin{array}{l}\mathrm{KClO}_{3}-78.57 \% \\
\mathrm{PE}-18.43 \% \\
\mathrm{Al}-3 \%\end{array}$ & $-3,280$ & 1,664 & 32.498 & 281.55 & 475.0 & 1.2272 & 5.7 \\
\hline 3 & $\begin{array}{l}\mathrm{KClO}-76.95 \% \\
\mathrm{PE}-18.05 \% \\
\mathrm{Al}-5 \%\end{array}$ & $-3,220$ & 1,852 & 32.909 & 293.66 & 543.86 & 1.2266 & 9.4 \\
\hline 4 & $\begin{array}{l}\mathrm{KClO}-75.33 \% \\
\mathrm{PE}-17.67 \% \\
\mathrm{Al}-7 \%\end{array}$ & $-3,150$ & 2,048 & 32.749 & 301.36 & 617.19 & 1.2124 & 13.4 \\
\hline 5 & $\begin{array}{l}\mathrm{KClO}-73.71 \% \\
\mathrm{PE}-17.29 \% \\
\mathrm{Al}-9 \%\end{array}$ & $-3,080$ & 2,231 & 32.595 & 309.8 & 691.2 & 1.194 & 17.0 \\
\hline 6 & $\begin{array}{l}\mathrm{KClO}-72.09 \% \\
\mathrm{PE}-16.91 \% \\
\mathrm{Al}-11 \%\end{array}$ & $-3,010$ & 2,285 & 32.445 & 313.63 & 716.6 & 1.183 & 18.6 \\
\hline 7 & $\begin{array}{l}\mathrm{KClO}-70.47 \% \\
\mathrm{PE}-16.53 \% \\
\mathrm{Al}-13 \%\end{array}$ & $-2,950$ & 2,053 & 34.415 & 324.42 & 666 & 1.2154 & 18.2 \\
\hline
\end{tabular}

Table-2: Calculated values of gas productivity of the test compositions

\begin{tabular}{|c|c|c|c|c|c|c|c|}
\hline \multirow[t]{2}{*}{ Parameter } & \multicolumn{7}{|c|}{ Composition No } \\
\hline & 1 & 2 & 3 & 4 & 5 & 6 & 7 \\
\hline $\begin{array}{c}\mathrm{V}_{\mathrm{n}}, 1 / \mathrm{kg} \\
(\mathrm{P}=0.1 \mathrm{MPa})\end{array}$ & 732.66 & 727.96 & 737.16 & 733.58 & 730.13 & 726.77 & 770.90 \\
\hline
\end{tabular}

As can be seen from Table-1, an increase in the aluminum content in the composition leads to an increase in the adiabatic temperature $\mathrm{T}_{\mathrm{ad}}$, the efficiency of the combustion products $\mathrm{RT}$ and the mass fraction of the condensed phases. The introduction of aluminum above $11 \%$ leads to a decrease in the value of these parameters. The introduction into the formulation of the investigated mixtures of aluminum from 1 to 13 wt. \% does not cause a significant change in the values of gas production (Table-2).

As an energy additive, aluminum powder grade PA-4 and aluminum nanopowder Alex were used to compare the combustion parameters of the test compositions. It is known ${ }^{2,19-21}$ that nanopowders of metals 
have an increased reactivity, the relevance of these systems is related to the peculiarity of their physicochemical properties in comparison with conventional materials. As a result of the study, it was established that the complete replacement of aluminum powder PA-4 with an ultrafine Alex powder leads to an increase in the combustion rate of the gas-generator composition by a factor of 2 . For this reason, Alex was chosen as an energy additive for further research.

For the comparative analysis of calculated data, an experimental study of the burning of these compositions was carried out. Table- 3 shows the values of the burning rate, the ignition delay time and the combustion temperature of the test samples.

Table-3: Experimental study of combustion parameters of test samples

\begin{tabular}{c|c|c|c}
\hline $\begin{array}{c}\text { Composition, No } \\
\left(\mathrm{KClO}_{3} \text {-PE-Alex }\right)\end{array}$ & $\begin{array}{c}\text { Ignition delay time, tign, } \\
\text { sec }\end{array}$ & Burning speed, $\mathrm{mm} / \mathrm{s}$ & $\begin{array}{c}\text { Burning } \\
\text { temperature, }{ }^{\circ} \mathrm{C}\end{array}$ \\
\hline 1 & $1.17 \pm 0.06$ & $0.77 \pm 0.06$ & 922 \\
\hline 2 & $1.1 \pm 0.2$ & $0.95 \pm 0.07$ & 957 \\
\hline 3 & $1.01 \pm 0.05$ & $1.11 \pm 0.29$ & 1,022 \\
\hline 4 & $0.85 \pm 0.29$ & $1.19 \pm 0.03$ & 1,047 \\
\hline 5 & $0.83 \pm 0.03$ & $1.27 \pm 0.05$ & 1,103 \\
\hline 6 & $0.75 \pm 0.02$ & $1.4 \pm 0.3$ & 1,160 \\
\hline 7 & $1.03 \pm 0.05$ & $1.17 \pm 0.02$ & 1,105 \\
\hline
\end{tabular}

As can be seen from the Table-3, the most optimal composition is sample No. 6, this composition has the highest burning rate and the shortest ignition delay time and shows a high temperature.

Thus, an increase in the content of nanoaluminum up to $11 \%$ allows to reduce the delay time of ignition, increase the speed and temperature of combustion. The received results of experimental work show good convergence with calculated values.

On the basis of the carried-out thermodynamic calculations and experimental works for the destruction of a stone the pyrotechnic gas-generating composition No.6 had been chosen: $\mathrm{KClO}_{3}-72$ of \%, \% PE-17, \% Alex-11 nano-aluminium.

In polygon conditions, researchers on the destruction of a stone by initiation of a charge of gas-generating composition were carried out by an incandescence spiral (nichrome). The range of scattering of separate pieces of a stone was 2-3 m.

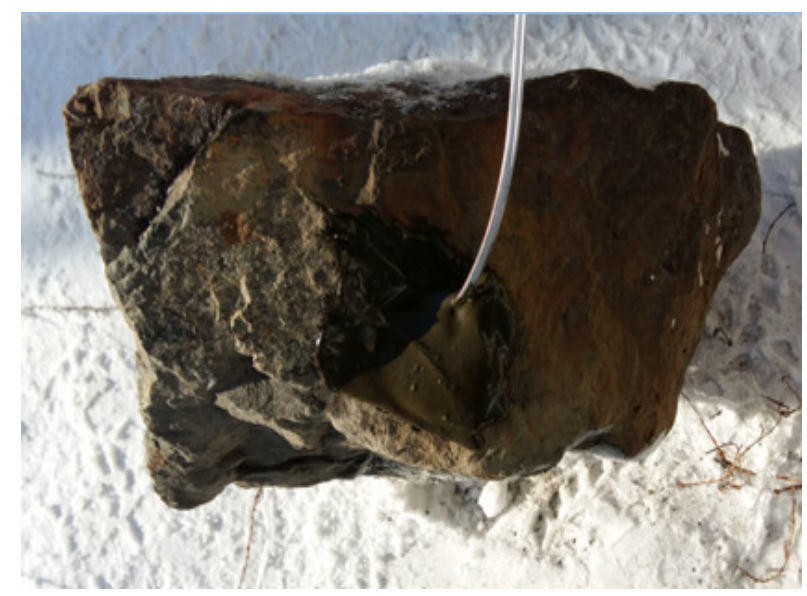

Fig.-2: A stone charged with a gas-generator charge

The mass of the composition in the gas-generator cartridge was $100 \mathrm{~g}$. After the pulse from the laboratory, autotransformer was applied to the filament, the charge was triggered and the stone was destroyed. Detonation impact, emission of toxic gases and combustion products were not observed. 


\section{CONCLUSION}

Influence of various amount of nanopowder of aluminum on characteristics of burning and ignition of gas-generating composition on the basis of potassium chlorate was studied. On the basis of the calculated and experimental data, it was found that more than $11 \%$ of aluminum was inexpedient to enter into the composition.

The gas-generating composition $\mathrm{KClO}_{3}-72 \%$, PE-17\%, nano-aluminum Alex-11\% for the destruction of stone was developed. The carried out researches and performed polygon researchers have shown high efficiency of application of this gas-generator composition for destruction of a stone.

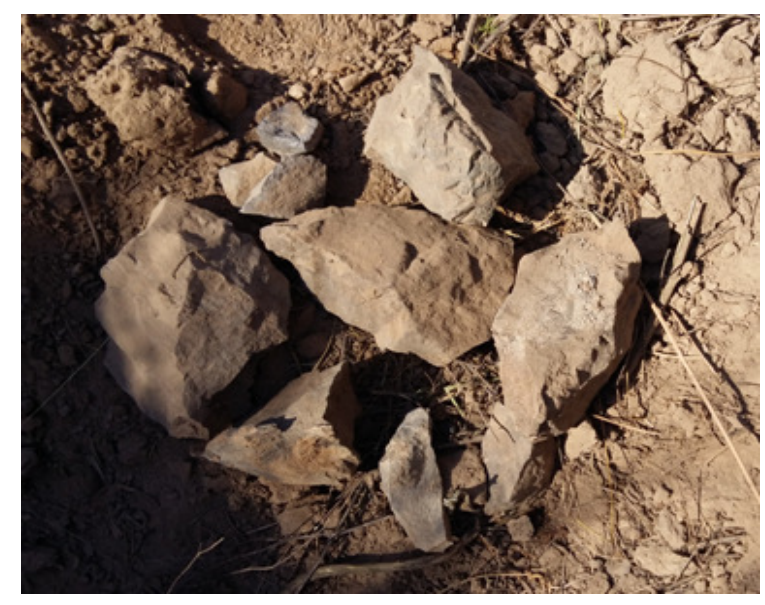

Fig.-3: The stone after combustion of the gas-generator composition

\section{REFERENCES}

1. J.C. Cleaveland, IEEE Software, 5(4), 25(1988).

2. D.A. Baiseitov, M.I. Tulepov, S. Tursynbek, L.R. Sassykova, M. Nazhipkyzy, Sh.E. Gabdrashova, Y.V. Kazakov, I.O. Pustovalov, F.Y. Abdrakova, Z.A. Mansurov, A.B. Dalton, Rasayan J. Chem., 10(2), 344(2017).

3. G.V. Sakovich, S.G. Il'yasov, I.V. Kazantsev, D.S. Il'yasov, A.A. Averin, M.V. Shatnyy, Polzunovskiy vestnik, 4, 47(2010).

4. R.F. Blanks, T.S. Wittrig, D.A. Peterson, Chem.Eng.Sci, 45(8), 2407(1990).

5. D.R. Greatrix, Energies, 3(11), 1790(2010).

6. A. Apelblat, E. Manzurola, The Journal of Chemical Thermodynamics, 39(8), 1176(2007).

7. D. Juknelevicius, A. Dufter, M.Rusan, Th.M. Klapötke, A. Ramanavicius, European Journal of Inorganic Chemistry, 7, 1113(2017).

8. R.K. Balan, A.Tatybekov, V.S. Engel'sht, Proceedings of the NAS of the Kyrgyz Republic,4, 68(2007).

9. R. M. Manohar, M. Prabhahar, S. Sendilvelan, European Journal of Scientific Research, 76(3), 327(2012).

10. S. Sendilvelan, K. Bhaskar, Orient J Chem, 33(4), 2111(2017).

11. L. Sassykova, A. Nalibayeva, Y.Aubakirov, Zh.Tashmukhambetova, U. Otzhan, N.Zhakirova, M.Faizullaeva, Orient J Chem, 33(4), 1941(2017).

12. S.Sendilvelan, K.Bhaskar, Rasayan J.Chem., 9(4), 692(2016).

13. D.A. Baiseitov, Sh.E. Gabdrashova, A.N. Magazova, O. Dalelkhanuly, Zh.B. Kudyarova, M.I. Tulepov, L.R. Sassykova, Z.A. Mansurov, Int. J. Chem. Sci., 14(1), 244(2016).

14. T.D. Manship, S.D. Heister, P.T. O'Neil, Journal of Propulsion and Power, 28(6), 1389(2012).

15. L.Sassykova, Sh.Gil'mundinov, A.Nalibayeva, I.Bogdanova. Revue Roumaine de Chimie, 62(2), 107(2017). 
16. B. G.Trusov, Inzhenernyy zhurnal: nauka i innovatsiy, 1, 2 (2012). DOI: 10.18698/2308-6033-2012$1-31$.

17. H.Jones, Metal Powder Report, 51(4), 46(1996). DOI:10.1016/0026-0657(96)92149-9.

18. S.M. Pourmortazavi, S.S. Hajimirsadeghi, I. Kohsari, M. Fathollahi, S.G. Hosseini, Fuel, $\quad$ 87(2), 244(2008).

19. D.A. Baiseitov, Sh.E. Gabdrashova, A.K. Akylbai, O. Dalelkhanuly, Zh.B. Kudyarova, L.R. Sassykova, M.I. Tulepov, Z.A. Mansurov, Int. J. Chem. Sci., 14(1), 261(2016).

20. E.G. Yao, F.Q. Zhao, S.Y. Xu, R.Z. Hu, H.X. Xu, H.X. Hao, Advanced Materials Research, 924 , 200(2014).

21. X. Kang, F. Yang, J. Luo, Y. Tang, Combustion Science and Technology, 187(6), 963(2015).

22. S.S. Klyukin, R.I. Rezyapov, Oil and Gas Business, 6, 378(2014).

[RJC-1878/2017] 